\title{
Evaluation of the Topical use of Essential Fatty Acids in Rabbits with Skin Disorders
}

\author{
Camilo Romero Núñez ${ }^{1}$, Galia Sheinberg Waisburd ${ }^{2}$, Alberto Martín Cordero ${ }^{3}$, Rafael \\ Heredia Cardenas ${ }^{4 *}$, Laura Reyes Clímaco ${ }^{1}$
}

\begin{abstract}
${ }^{1}$ Dermavet Hospital Veterinario, José de la Luz Blanco, Mz. 187, Lt. 33, Col. Santa Martha Acatitla, Ciudad de México; ${ }^{2}$ Centro Veterinario México, Calle Cincinnati \#22, Benito Juárez, Ciudad de los Deportes, 03710 Ciudad de México, México; ${ }^{3}$ Vetderm Dermatologia Veterinaria Especializada Av Niños Héroes 1665, Guadalajara, México; ${ }^{4}$ Centro Integral Veterinario CIVET, Valle del Don Mz 374 Lt. 14B Col. Granjas Independencia, Ecatepec de Morelos, México.
\end{abstract}

\begin{abstract}
Omega-3 and -6 fatty acids are used in animals for the management of various diseases, many of which are inflammatory in nature. In recent years, the use of essential fatty acids in dermatological conditions has gained interest. The objective of this research was to evaluate the efficacy of a commercial topical solution, composed of essential fatty acids (omega-3 and -6) and natural extracts, in 30 New Zealand rabbits with signs of dry skin, opaque/brittle coat, excessive hair loss, desquamation, and/or bad odor, of both sexes and an average weight of $2.5 \mathrm{~kg}$. The rabbits were randomly divided into 2 groups; 15 were treated with the mousse topical solution, composed of hemp oil, essential fatty acids (omega-3 and -6), niaouli essential oil, lichen extract, calming extract from pumpkin seeds, saponaria root extract, and green apple lipoamino acids. The product was applied twice a week for 5 weeks. The rabbits were evaluated on days 1,14,28, and 35. From day 14, there were significant differences between the topical treatment group and the control group (no topical application). There was an improvement in the skin conditions, with a reduction in hair loss, as well as a decrease in bad odor and desquamation. In the same way, a statistically significant association between the groups was observed from day 14 . Topical therapy with essential fatty acids and natural extracts can offer an effective alternative for the successful treatment of skin disorders in rabbits.
\end{abstract}

Keywords | Fatty acids, Omega-3 and -6, Rabbits, Topical, Skin disorders

Received | November 03, 2021; Accepted | December 01, 2021; Published | December 17, 2021

*Correspondence | Rafael Heredia Cardenas, Centro Integral Veterinario CIVET, Valle del Don Mz 374 Lt. 14B Col. Granjas Independencia, Ecatepec de Morelos, México; Email: rafaesbirro@hotmail.com

Citation | Núñez CR, Waisburd GS, Cordero AM, Cardenas RH, Climaco LR (2021). Evaluation of the topical use of essential fatty acids in rabbits with skin disorders. Res J. Vet. Pract. 9(4): 30-33.

DOI | http://dx.doi.org/10.17582/journal.rjvp/2021/9.4.30.33

ISSN | 2308-2798

Copyright (C) 2021 Heredia et al. This is an open access article distributed under the Creative Commons Attribution License, which permits unrestricted use, distribution, and reproduction in any medium, provided the original work is properly cited.

\section{INTRODUCTION}

$\mathrm{R}$ abbits are popular pets (Davies, 2010). Over the years, adoption of these pets has been increasing (Shepherd, 2008), which is why rabbits are becoming more frequent visitors to veterinary clinics (Moyes, 2014). According to Jenkins (2001), skin disorders in rabbits are very common, presenting a major problem in the species (Stand and Rowland, 2011). Among the most frequent skin disorders are pododermatitis, abscesses, alopecia, external otitis, and ectoparasitic infections (Snook et al., 2013). Some pathologies of the skin are related to vitamins such as A, D, E, and $\mathrm{C}$, essential fatty acids, proteins, and some minerals (Gonzalez, 2016). It has been reported that supplement administration, such as essential fatty acids, can have a beneficial effect on animals with skin disorders by improving the quality of the coat, strengthening the skin barrier, and reducing the trans-epidermal loss of water, in addition to reducing the administration of glucocorticoids (Gedon and Mueller, 2018). The objective of this research was to evaluate the efficacy of a commercial topical solution composed of essential fatty acids (omega-3 and -6) and natural extracts in rabbits with skin disorders. 


\section{MATERIALS AND METHODS}

The present study was developed at the Veterinary School UAEM Amecameca University Center. The study was reviewed and endorsed by the ethics committee of the Autonomous University of the State of Mexico. The procedures performed on the animals were carried out according to the Mexican standards for the practices of care of experimental animals (NOM-062-ZOO-1999). It was a double-blind study. Thirty New Zealand rabbits of both sexes, the base etiology was not determined, only rabbits with skin and fur alterations were considered and with an average weight of $2.5 \mathrm{~kg}$. The animals were fed a commercial rabbit diet and water ad libitum, and all animals were kept in individual cages. The inclusion criteria consisted of signs such as dry skin, oil loss, dull/brittle coat, excessive hair loss, and/or bad odor. Rabbits that had received some type of topical or systemic pharmacological treatment were excluded.

The rabbits were randomly divided into two groups; 15 were treated with the topical solution Essential Mousse ${ }^{\circledR}$ (Dermoscent ${ }^{\circledR}$ ), which contains hemp oil, essential fatty acids (omega-3 and -6), essential oil of niaouli, an extract of lichen, and a calming agent extracted from pumpkin seeds. The cleaning base was formulated with a root extract of saponaria and green apple lipoamino acids.

For each rabbit, $3 \mathrm{~mL}$ of mousse was applied to the animal's coat, massaging opposite the direction of fur growth. The excess was removed with a towel, then the coat was allowed to dry and then brushed. This application was performed 2 times per week, for 5 weeks. The other 15 rabbits were treated as a control group. The same procedure was performed, and as a placebo, three $\mathrm{ml}$ of water was applied topically. The 30 rabbits were evaluated on days 1 (day 1 applies the product and evaluates it as a start), 14, 28, and 35 by observing clinical signs in the face, head, neck, sternum, groin, abdomen, back, sides, front end, posterior end, perianal and perigenital regions, and tail. The evaluation of the clinical signs was based on the following criteria: A) condition and shine of the coat $(1=$ very matted, $2=$ matted, $3=$ little matting, $4=$ normal, $5=$ little shine, $6=$ shiny); $\mathrm{B}$ ) hair loss ( $1=$ very severe, $2=$ severe, $3=$ moderate, $4=$ light, $5=$ poor $)$; ) scaling and odor $(1=$ very bad, $2=$ bad, 3 = acceptable, 4 = good, $5=$ nice); D) oily or dry skin or fur ( $1=$ very oily, $2=$ oily, $3=$ slightly oily, $4=$ normal, 3 = slightly dry, 2 = dry, 1 = very dry). The evaluation of clinical results and signs were carried out by the same qualified veterinary physician, comparing the skin and coat score in rabbits treated with Essential Mousse ${ }^{\circledR}$ (Dermoscent $^{\circledR}$ ) and the control group, with four measurable evaluation points (A-D).
The evaluations of the skin, coat, and their conditions were statistically evaluated by the Shapiro-Wilk normality test to determine the distribution and Tukey's studentized rank test and the Kruskal-Wallis test to compare the variables between both groups. The value of $\mathrm{P}<0.05$ was considered significant.

\section{RESULTS}

All significance assessment points except day 1 between control group and treatment group. As of day 14, significant differences were found between the topical treatment group and the control group (Table 1). On days 28 and 35 , an improvement in coat brightness and a decrease in coat loss were observed ( $\mathrm{P}=0.0001$ y $\mathrm{P}=0.001$, respectively). The presence of desquamation also had significant differences between groups $(\mathrm{P}=0.0002)$; the treatment increased this score in each evaluation, and the control group had decreased values. Regarding the odor evaluation, an improvement was observed from day 14 . The variable for oily vs. dry skin/hair showed similar results; the treatment group remained at a stable score of around 4 (normal skin/ hair), and the control group decreased its score with values around 3 (skin/hair slightly oily/dry), presenting significant differences on days 14,28 , and 35 . It should be noted that no adverse effects were observed in any of the treated rabbits. No improvement in clinical signs was observed in the control group.

\section{DISCUSSION}

In recent years, the use of complementary and alternative treatments has become more common in the fields of medicine and dermatology (Orchard and Van Vuuren, 2017). The use of plant extracts and essential oils has been analyzed globally to control multi-drug resistant pathogenic microorganisms (Reichling et al., 2009; Swamy et al., 2016). Essential fatty acids such as omega- 6 are involved in maintaining the permeability of water through the skin barrier, while omega-3 is related to modulation of the inflammatory response and a decrease in itching intensity (Kirby et al., 2007). This could explain the improvement observed in this investigation, in terms of the brightness of the fur in the rabbits treated with essential fatty acids (omega-3 and -6).

It has been shown that essential oils have antiseptic, antibacterial, antiviral, antioxidant, antiparasitic, antifungal, and insecticidal properties (Chouhan et al., 2017). This matches what was reported in this investigation, in which rabbits treated with essential oils improved in terms of dermatological assessments (brightness of fur, hair loss, sca mosis, smell, and oily vs. dry hair/skin). These results are also similar to those of Tretter and Mueller (2011) who 
Table 1: Comparison of means between study variables in rabbits treated with Essential Mousse ${ }^{\circledR}\left(\right.$ Dermoscent $\left.^{\circledR}\right)$ and the control group.

\begin{tabular}{|c|c|c|c|c|}
\hline & Day 1 & Day 14 & Day 28 & Day 35 \\
\hline \multicolumn{5}{|l|}{ Brittle coat } \\
\hline Treatment & 2.00 & 2.46 & 4.40 & 5.00 \\
\hline Control & 2.13 & 2.13 & 2.20 & 2.06 \\
\hline Chi-Square & 0.00 & 21.60 & 23.49 & 23.30 \\
\hline $\mathrm{p}$ & 1.00 & $0.0001^{*}$ & $0.0001^{*}$ & $0.0001^{*}$ \\
\hline \multicolumn{5}{|c|}{ Excessive hair loss } \\
\hline Treatment & 4.53 & 4.86 & 6.46 & 6.86 \\
\hline Control & 4.26 & 3.00 & 2.46 & 2.26 \\
\hline Chi- Square & 0.40 & 13.21 & 23.68 & 26.07 \\
\hline $\mathrm{p}$ & 0.52 & $0.0003^{*}$ & $0.0001^{*}$ & $0.0001^{*}$ \\
\hline \multicolumn{5}{|l|}{ Scamosis } \\
\hline Treatment & 4.93 & 5.80 & 6.40 & 6.66 \\
\hline Control & 4.53 & 2.26 & 2.06 & 2.00 \\
\hline Chi- Square & 0.76 & 14.13 & 21.94 & 24.62 \\
\hline $\mathrm{P}$ & 0.38 & $0.0002^{*}$ & $0.0001^{*}$ & $0.0001^{*}$ \\
\hline \multicolumn{5}{|l|}{ Odor } \\
\hline Treatment & 3.53 & 5.13 & 5.66 & 5.86 \\
\hline Control & 4.00 & 3.13 & 2.46 & 2.13 \\
\hline Chi- Square & 0.40 & 20.39 & 23.77 & 24.25 \\
\hline $\mathrm{P}$ & 0.52 & $0.0001^{*}$ & $0.0001^{*}$ & $0.0001^{*}$ \\
\hline \multicolumn{5}{|c|}{ Dry skin, oil loss, dull } \\
\hline Treatment & 3.53 & 3.80 & 3.80 & 3.93 \\
\hline Control & 3.20 & 2.86 & 3.06 & 2.66 \\
\hline Chi- Square & 0.64 & 9.96 & 7.70 & 20.66 \\
\hline $\mathrm{P}$ & 0.42 & $0.0016^{*}$ & $0.0055^{*}$ & $0.0001^{*}$ \\
\hline
\end{tabular}

Kruskal Wallis test, $P<0.05$. ${ }^{*}$ Statistically significant value

studied seven dogs with skin infections with bacteria such as Staphylococcus pseudintermedius and yeasts such as Malassezia pachydermatis. The dogs were treated with a topical solution containing fatty acids and essential oils, with an application every 7 days, for 8 weeks. The dogs showed a significant decrease in signs such as erythema, lichenization, excoriation, and alopecia, indicating that fatty acids and essential oils are a useful option for the treatment of secondary signs of infection. These results are similar to those in this research, in which the topical use of essential oils and fatty acids in rabbits showed decreased hair loss and flaking from 14 days. It has been reported that foul odor can be caused by a great diversity of bacteria, although there are no reports of the use of essential oils and fatty acids in rabbits to reduce the smell Meason et al. (2018) reported that the topical use of essential oils and fatty acids in dogs with a foul smell caused by Psychrobacter spp. and Pseudomonas spp. significantly decreased $(\mathrm{P}=0.0078)$ the odor. This coincides with the decrease $(\mathrm{P}=0.0001)$ in odor of the rabbits in this study, starting on day 7 of treatment with essential oils and fatty acids. Another study reported an experiment conducted on 48 dogs of different breeds, ages, and genders, diagnosed with atopic dermatitis, and treated with a formulation of fatty acids and essential oils, once a week, for 8 weeks. The dogs were evaluated before and after treatment using the severity of signs and pruritus scores, and there was a significant improvement of $50 \%$ (Blaskovic et al., 2014). This was unlike the results of this study, in which significant improvement was observed in most rabbits evaluated (90\%). However, the study only lasted for 5 weeks, so treatment is suggested for longer periods of time.

The topical use of fatty acids (omega-3 and -6) and natural extracts might be effective alternative for the successful treatment-without side effects-of skin disorders in rabbits. 


\section{CONFLICT OF INTEREST}

The authors declare that they have no conflict of interest.

\section{AUTHOR CONTRIBUTIONS}

Camilo Romero, Galia Sheinberg and Alberto Martín contributed conception and design of the experiment. Camilo Romero, Laura Reyes conducted the experiment, Rafael Heredia organized the database, Rafael Heredia performed the statistical analyses, Camilo Romero, Galia Sheinberg, Alberto Martín, Rafael Heredia, Laura Reyes wrote the manuscript, All authors contributed to manuscript revision, read, and approved the submitted version.

\section{FUNDING}

The study was self-funded.

\section{REFERENCES}

-Blaskovic M, Rosenkrantz W, Neuber A, Sauter-Louis C, Mueller RS (2014). The effect of a spot-on formulation containing polyunsaturated fatty acids and essential oils on dogs with atopic dermatitis. Vet. J. 199: 39-43. https://doi. org/10.1016/j.tvj1.2013.10.024.

- Chouhan S, Sharma K, Guleria S (2017). Antimicrobial Activity of Some Essential Oils-Present Status and Future Perspectives. Medicines. (Basel). 4: E58. https://doi. org/10.3390/medicines4030058.

-Davies M. (2010). Preventive medicine for pet rabbits. VNJ. 25: 55-59. https://doi.org/10.1111/j.2045-0648.2010. tb00036.x

- Gedon NKY, Mueller RS (2018). Atopic dermatitis in cats and dogs: a difficult disease for animals and owners. Clin. Transl. Allergy. 8: 41. https://doi.org/10.1186/s13601-018-0228-5

- Gonzalez MS (2016). Patologías dermatológicas de origen nutricional en los pequeños anima-les: una revisión. Rev. CES Med. Zootec. 11: 82-102.

-Jenkins JR (2001). Skin disorders of the rabbit. Vet. Clin. North. Am. Exot. Anim. Pract. 4: 543-63. https://doi.org/10.1016/

S1094-9194(17)30042-7

- Kirby NA, Hester SL, Bauer JE (2007). Dietary fats and the skin and coat of dogs. J. Am. Vet. Med. Assoc. 230: 1641-4. https://doi.org/10.2460/javma.230.11.1641

- Meason SC, Older CE, Ocana R, Dominguez B, Lawhon SD, Wu J (2018). Novel association of Psychrobacter and Pseudomonas with malodour in bloodhound dogs, and the effects of a topical product composed of essential oils and plant-derived essential fatty acids in a randomized, blinded, placebo-controlled study. Vet. Dermatol. 29: 465-e158. https://doi.org/10.1111/vde.12689

-Moyes S (2014). Caring for rabbits in practice. VNJ. 29: 123125. https://doi.org/10.1111/vnj.12128

-NORMA Oficial Mexicana NOM-062-ZOO-1999, Especificaciones técnicas para la producción, cuidado y uso de los animales de laboratorio. Available in: https://www. gob.mx/cms/uploads/attachment/file/203498/NOM-062ZOO-1999_220801.pdf

- Orchard A, Van Vuuren S (2017). Commercial Essential Oils as Potential Antimicrobials to Treat Skin Diseases. Evid. Based. Complement. Alternat. Med. 2017: 4517971. https:// doi.org/10.1155/2017/4517971

- ReichlingJ, Schnitzler P,Suschke U, Saller R (2009). Essential oils of aromatic plants with antibacterial, antifungal, antiviral, and cytotoxic properties-an overview. Forsch. Komplementmed. 16: 79-90. https://doi.org/10.1159/000207196

- Shepherd AJ (2008). Results of the 2006 AVMA survey of companion animal ownership in US pet-owning households. J. Am. Vet. Med. Assoc. 232: 695-696. https:// doi.org/10.2460/javma.232.5.695

-Snook TS, White SD, Hawkins MG, Tell LA, Wilson LS, and Outerbridge CA (2013). Skin diseases in pet rabbits: a retrospective study of 334 cases seen at the University of California at Davis, USA (1984-2004). Vet. Dermatol. 24: 613-e148. https://doi.org/10.1111/vde.12087

-Stand R, Rowland M (2011). Skin disease in rabbits. In. Practice. 31: 233-238.

- Swamy MK, Akhtar MS, Sinniah, UR (2016). Antimicrobial Properties of Plant Essential Oils against Human Pathogens and Their Mode of Action: An Updated Review. Evid. Based. Complement. Alternat. Med. 2016: 3012462. https:// doi.org/10.1155/2016/3012462

- Tretter S, Mueller RS (2011). The Influence of Topical Unsaturated Fatty Acids and Essential Oils on Normal and Atopic Dogs. J. Am. Anim. Hosp. Assoc. 47: 236-240. https://doi.org/10.5326/JAAHA-MS-5607 